\title{
Effect of particle size on the physicochemical and morphological properties of Hypsizygus marmoreus mushroom powder and its hot-water extracts
}

\author{
Emmanuel Hitayezu ${ }^{1}$, Yoon-Han Kang ${ }^{1,2 *}$ \\ ${ }^{1}$ Department of Food Processing and Distribution, Gangneung-Wonju National University, Gangneung 25457, Korea \\ ${ }^{2}$ East Coast Research Institute of Life Science, Gangneung-Wonju National University, Gangneung 25457, Korea
}

\begin{abstract}
Hypsizygus marmoreus, an edible mushroom with various functional properties, was prepared to obtain coarse and superfine powders. We evaluated the effect of particle size on mushroom powder quality. The water absorption index and total dietary fiber contents of superfine powders (average median diameter, $4.791 \mu \mathrm{m}$ ) were $5.79 \mathrm{~g} / \mathrm{g}$ and $28.50 \mathrm{~g} / 100 \mathrm{~g}$, respectively, which were higher than the corresponding values of coarse powder (average median diameter, $168.085 \mu \mathrm{m})$. Similarly, extracts prepared from the superfine mushroom powders exhibited higher total polyphenolics contents $(83.91 \mathrm{mgGAE} / 100 \mathrm{~g})$, total sugar contents $(5,138.50 \mathrm{mg} / 100 \mathrm{~g})$, and total flavonoid contents (43.99 $\mathrm{mgNE} / 100 \mathrm{~g}$ ) compared with those prepared from coarse mushroom powders. The extraction yield and $\mathrm{pH}$ were higher for superfine powder concentrates than for coarse powder concentrates. According to the electronic tongue results, superfine powder extracts had high scores for umami, sourness, and sweetness, while coarse powder extracts scored high in bittemess. Furthermore, SEM images indicated that both powders differed in either the shape or size of the particles; coarse powder particles exhibited irregular shapes and high porosity, while superfine powder particles represented a uniform shape and lower porosity. Particle size reduction through superfine grinding improved the physicochemical and morphological properties of the mushroom powder samples and their hot-water extracts.
\end{abstract}

Key words : Hypsizygus marmoreus, particle size, superfine powder, physicochemical properties, morphological properties

\section{Introduction}

Hypsizygus marmoreus is an edible mushroom species that is widely grown in East Asian countries such as Japan, Taiwan, and South Korea. This mushroom has been reported to possess anti-inflammatory, antifungal, antitumor, and antioxidant properties (Lee et al., 2007; Suzuki et al., 2011); the use of $H$. marmoreus has there became increasingly popular in several countries, including Taiwan (Lee et al., 2008).

Superfine grinding is a modern food processing technology that has been applied to various food materials, including ginseng, fruits, cereals, and mushrooms (Seo et al., 2011; Shu et al., 2004). Pulverization of food materials using a jet mill (an air flow-type grinder) allows superfine grinding that yields a particle size of up to several micrometers. The micronization process in the jet mill helps to improve texture and digestion, maintain color and flavor, and control the rate of nutrient absorption. The use of superfine grinding technology in the production of red grape pomace powder and green tea powder can broaden the application of these natural materials (Hu et al., 2012; Zhao et al., 2015). Ming et al. (2014) and Choi et al. (2012) have reported the effect of particle size on the quality of Lentinus edodes mushroom

\footnotetext{
*Corresponding author. E-mail : yhkang@gwnu.ac.kr, Phone : +82-33-640-2966, Fax : +82-33-640-2966

Received 17 May 2021; Revised 24 June 2021; Accepted 13 July 2021.

Copyright (c) The Korean Society of Food Preservation.

This is an Open Access article distributed under the terms of the Creative Commons Attribution Non-Commercial License (http://creativecommons.org/licenses/by-nc/4.0) which permits unrestricted non-commercial use, distribution, and reproduction in any medium, provided the original work is properly cited.
} 
powder and Angelica gigas powder, respectively. Although previous studies focused on hot-water extraction of $H$. marmoreus mushroom powder and its properties, none have investigated the effect of particle size on the powder or extracts of this mushroom.

This study analyzed the physicochemical properties of extracts prepared from coarse and superfine powders of $H$. marmoreus mushroom using microparticle technology. Our results provide a basis for the development of highvalue-added foods using superfine powders and their extracts.

\section{Materials and methods}

\section{Sample preparation}

Fresh and cold-air-dried H. marmoreus mushrooms were purchased from World Farm, a farming company in Yangyang, Gangwon-do, Korea and stored in a refrigerator. The air-dried mushrooms were pulverized using a blade grinder (Hanil Electronics Co. Ltd, Gyeonggi-do, South Korea) for $2 \mathrm{~min}$ to obtain a coarse powder. To obtain a superfine powder, we first coarsely ground air-dried mushrooms using a cutter mill and, subsequently, finely ground them using a blade mill, followed by jet milling (Jet mill, Korea Powder System Co., LTD, Incheon, Korea).

\section{Analysis of particle sizes}

The particle sizes of coarse and superfine mushroom powders were analyzed using the method described by Zhou and Kang (2018) with a particle size analyzer (Mastersizer 2000, Malvern Instruments Ltd., UK). Distilled water at room temperature was used as the dispersant, and the dispersant refractive index was 1.330 . The particle refractive index and absorption set at 1.520 and 0.1 , respectively, while the obscuration was set at $3.00 \%$ for coarse powder and $4.49 \%$ for superfine powder.

\section{Hot-water extraction of Hypsizygus marmoreus mushroom powders}

H. marmoreus mushroom extracts were obtained by extracting coarse powder or superfine mushroom powder (45 $\mathrm{g})$ in boiling distilled water $(1.5 \mathrm{~L})$ for $1 \mathrm{~h}$, followed by concentration of the hor-water extract to $100 \mathrm{~mL}$ under reduced pressure at $50^{\circ} \mathrm{C}$ using a vacuum extractor (Rikakikai
Co., Ltd, Tokyo, Japan). The extracts were refrigerated until further use.

\section{Determination of water absorption index and water solubility index}

The water absorption index (WAI) and water solubility index (WSI) were determined using the method establsihed by Yousf et al. (2017). Briefly, coarse or superfine mushroom powder $(0.5 \mathrm{~g})$ was mixed with distilled water $(10 \mathrm{~mL})$ in a centrifuge tube, incubated at $30^{\circ} \mathrm{C}$ in a constant temperature water bath for $30 \mathrm{~min}$, and centrifuged at 3,000 $\times g$ for $10 \mathrm{~min}$. The sediments that remained after removal of the supernatant were used to ascertain the WAI.

For WSI determination, the supernatants were evaporated in an oven drier at $105^{\circ} \mathrm{C}$ for $3 \mathrm{~h}$ on glass Petri dishes. After evaporation, the Petri dishes were cooled in a desiccator and weighed. The obtained weights were used to calculate WSI.

WAI $(\mathrm{g} / \mathrm{g})=$ Weight of sediment $/$ Weight of sample

WSI $(\%)=($ Weight of dry supernatant $/$ Weight of sample $)$ $\times 100$

\section{Determination of beta glucan content}

The $\beta$-glucan content of mushroom powders was determined following the method described by Bak et al. (2014) using a yeast-specific $\beta$-glucan kit provided by Megazyme International. The analysis protocol described by the kit manufacturer was followed. The MegaCalc Excel sheet obtained from the Megazyme website was used for calculations. $\beta$-Glucan content was calculated as the difference between total glucan content and $\alpha$-glucan content.

\section{Determination of total dietary fiber contents}

Total dietary fiber contents of the mushroom powder samples was evaluated according to the general test method of the Korea Food Code (available at https://www. foodsafetykorea.go.kr/portal/safefoodlife/food/foodRvlv/food Rvlv.do). Briefly, in a beaker, mushroom powder $(1+0.005$ g) was mixed with MES/TRIS buffer solution $(40 \mathrm{~mL})$ and thermophile $\alpha$-amylase $(50 \mu \mathrm{L})$, and the mixture was incubated in a water bath at $95^{\circ} \mathrm{C}$ for $40 \mathrm{~min}$. Later, the water bath temperature was reduced to $60^{\circ} \mathrm{C}$ and protease enzyme $(100 \mu \mathrm{L})$ was added and incubated for $30 \mathrm{~min}$. The $\mathrm{pH}$ of the mixture was adjusted to $4.0-4.7$, using $0.56 \mathrm{~N} \mathrm{HCl}$ 
$(5 \mathrm{~mL})$ following which amyloglucosidase enzyme $(300 \mu \mathrm{L})$ was added, and the mixture was stirred for $30 \mathrm{~min}$ at $60^{\circ} \mathrm{C}$. Next, $95 \%$ ethanol $(225 \mathrm{~mL})$ heated at $60^{\circ} \mathrm{C}$ was added to the digested samples at an ethanol-to-sample ratio of 4:1. The beaker was removed from the water bath and covered with aluminum foil; the mixture was allowed to settle at room temperature for $1 \mathrm{~h}$. We dispersed the diatomaceous earth by adding $78 \%$ ethanol $(15 \mathrm{~mL})$ to a glass filter that had been weighed in advance with diatomaceous earth, followed by suction filtration to ensure that the diatomaceous earth layer was evenly formed. Next, the ethanol-treated enzyme digest was filtered through the prepared glass filter. The residue of the beaker was transferred to another glass filter using a washing bottle containing $78 \%$ ethanol and washed twice with $15 \mathrm{~mL}$ of $78 \%$ ethanol, $95 \%$ ethanol, and acetone, separately.

The glass filter with residual residue was dried at $105^{\circ} \mathrm{C}$ overnight, cooled in a desiccator for $1 \mathrm{~h}$ to constant weight; the glass filter, including the dietary fiber residue and diatomaceous earth, was weighed. The weight of the dietary fiber residue was calculated by subtracting the weight of the glass filter, including the diatomaceous earth. One of the two samples was measured for protein content where 6.25 was used as the nitrogen coefficient. The ash content was analyzed by incinerating the sample at $525^{\circ} \mathrm{C}$ for $5 \mathrm{~h}$, cooling in the desiccator, and measuring the weight of the dried crucible containing incinerated samples. The weight of the ash was determined by subtracting the weight of the crucible containing diatomaceous earth. Total dietary fiber was calculated by subtracting the weight of ash and protein from the weight of the residues, and the results were expressed as a percentage.

\section{Measurement of extraction yield}

The extraction yield of mushroom powders was measured according to the method described by Kim and Kim (2015). For dry weight measurements, the extracts of coarse and superfine mushroom samples were evaporated at $105^{\circ} \mathrm{C}$ for $3 \mathrm{~h}$ for the complete removal of distilled water, cooled in a desiccator, and subsequently weighed.

\section{Measurement of $\mathrm{pH}$ and total soluble solids}

The $\mathrm{pH}$ of mushroom concentrates was measured using a $\mathrm{pH}$ meter (pH 210, Hanna, Woonsocket, RI, USA) according to the method described by Lee et al. (2016) while total soluble solid content was measured using a hand refractometer (Atago., Ltd, Tokyo, Japan).

\section{Determination of total sugar contents}

Total sugar contents was determined according to the method described by Dai et al. (2010). Briefly, mushroom extract $(0.5 \mathrm{~mL}), 5 \%$ phenol solution $(0.5 \mathrm{~mL})$, and $95 \%$ sulfuric acid $(2.5 \mathrm{~mL})$ were added to a test tube and mixed using a vortex mixer. The reaction mixture was allowed to stand for $5 \mathrm{~min}$ at room temperature and then incubated in a water bath at $25^{\circ} \mathrm{C}$ for $15 \mathrm{~min}$. The absorbance was read at $490 \mathrm{~nm}$ using a spectrophotometer (Cary8454 UV-Vis, Agilent Technologies) and glucose was used for standardcurve generation.

\section{Determination of total polyphenol contents}

The total polyphenol contents of mushroom extracts was determined following the method described by Pinto et al. (2007) with minor modifications. Briefly, Folin-Ciocalteu reagent $(0.25 \mathrm{~mL})$ was added to the sample $(0.25 \mathrm{~mL})$; distilled water $(2 \mathrm{~mL})$ was added to this mixture, which was mixed using a vortex mixer. The reaction mixture was allowed to stand at room temperature for $3 \mathrm{~min}$, followed by the addition of $20 \% \mathrm{Na}_{2} \mathrm{CO}_{3}(0.25 \mathrm{~mL})$ and incubation in a water bath at $37^{\circ} \mathrm{C}$ for $30 \mathrm{~min}$. The absorbance was measured at $750 \mathrm{~nm}$ using a spectrophotometer (Cary8454 UV-Vis, Agilent Technologies) and gallic acid was used for creating a calibration curve.

\section{Determination of total flavonoid contents}

The total flavonoid contents of the mushroom extracts was determined as described by Kang et al. (2019). Briefly, diethylene glycol $(10 \mathrm{~mL})$ was added to the sample $(1 \mathrm{~mL})$, followed by vigorous mixing and addition of $\mathrm{NaOH}(1 \mathrm{~N}$; $1 \mathrm{~mL}$ ). This reaction mixture was vortexed and incubated in a water bath at $37^{\circ} \mathrm{C}$ for $1 \mathrm{~h}$. The absorbance was measured at $420 \mathrm{~nm}$ using a Cary $8454 \mathrm{UV}$-Vis spectrophotometer (Agilent Technologies) and naringin used for calculating the standard curve.

\section{Analysis of morphological properties of Hypsizygus marmoreus mushroom powders}

The microstructures of the mushroom powders were 
analyzed using a field-emission scanning electron microscope (SEM) (JSM-7500F; JEOL Ltd., Tokyo, Japan) using the method described by Zhou and Kang (2018). The coarse or superfine mushroom powder was coated on the SEM stub which had a double-sided, sticky tape on its surface. After the samples were placed on the stub surface, they were sputter-coated in vacuum using a gold sputter machine (LEICA EM SCD005, Austria). Images of the samples were recorded using a JSM-7500F field-emission SEM at 1,000× and 2,000× magnification for the coarse and superfine powders, respectively.

\section{Analysis of taste and odor characteristics}

The taste characteristics of the coarse and superfine mushroom extracts were analyzed using an ASTREE electronic tongue (E-tongue) (Alpha M.O.S, Toulouse, France) equipped with an auto-sampler and the following sensors, PKS and CPS (to detect complex taste) (Han et al., 2021), AHS (sourness), CTS (saltiness), NMS (umami), ANS (sweetness), and SCS (bitterness) sensors. We used the method described by Beullens et al. (2007) and Dong et al. (2019) to analyze the taste characteristics of the mushroom extracts. Briefly, the mushroom extracts prepared by extracting $45 \mathrm{~g}$ in distilled water $(1.5 \mathrm{~L})$ were concentrated to $200 \mathrm{~mL}$ and filtered through Whatman No. 2 filter paper. These extracts were used for the analysis of taste characteristics. Prior to the analysis, the electronic tongue sensors and system were calibrated and diagnosed using $0.01 \mathrm{M}$ sodium-L-glutamate. For the analysis, filtered extracts $(25 \mathrm{~mL})$ were used, and all samples were analyzed in five replicates. The analysis parameters were set to $0 \mathrm{~s}$ for delay; $120 \mathrm{~s}$, acquisition time; $1 \mathrm{~s}$, interval; 1 , stirring rate; and $1 \mathrm{~s}$, acquisition period. After the measurement of each sample (5 replicates), the sensors were rinsed with double-distilled water $(25 \mathrm{~mL})$.

During the determination of odor characteristics of mushroom extracts, the samples were extracted in a manner similar to the preparation of electronic tongue samples. mushroom extracts were analyzed following a modification of the method by Zhou et al. (2017) and Koh et al. (2020) using Heracles II electronic nose (E-nose) (Alpha MOS, H2-0087; France). This electronic nose consists of an auto sampler, two capillary columns with different polarities (MXT-5, polar and MXT-1701, slightly polar), and two flame ionization detectors (FID). The extracts $(5 \mathrm{~mL})$ were pipetted and sealed in $20 \mathrm{~mL}$ vials and analyzed according to the following analytical conditions: carrier gas, $99.995 \%$ hydrogen gas; oven, injector, trap, valve, and detector temperature were $40^{\circ} \mathrm{C}, 200^{\circ} \mathrm{C}, 40^{\circ} \mathrm{C}, 250^{\circ} \mathrm{C}$ and $250^{\circ} \mathrm{C}$, respectively. The injector pressure was set at $25 \mathrm{kPa}$, injector vent flow and split flow were both set at 10 $\mathrm{mL} / \mathrm{min}$, the FID temperature was $270^{\circ} \mathrm{C}$, and the acquisition time was $120 \mathrm{~s}$. For each sample, five replicates were analyzed. The ASTREE electronic tongue and Heracles II electronic nose are both equipped with statistical software, which was used for the determination of the function analysis for E-tongue and E-nose, respectively.

\section{Statistical analysis}

Experiments were conducted in triplicate, and the results are expressed as mean $\pm \mathrm{SD}$ except total dietary fiber and particle size distribution. The significance of the statistical difference of the obtained data was analyzed by an independent two-tailed $\mathrm{t}$ test using the SPSS software (Version 21 software, IBM, USA).

\section{Results and discussion}

\section{Particle size distribution}

The particle size distribution of the mushroom samples were reported as $\mathrm{d}(0.1), \mathrm{d}(0.5)$ and $\mathrm{d}(0.9) ; \mathrm{d}(0.1)$ and $\mathrm{d}(0.9)$ represent, respectively, the particle size values below which $10 \%$ and $90 \%$ of the volume is distributed, $\mathrm{d}(0.5)$ is the average median diameter; $50 \%$ of the volume distribution is above this particle size volume and $50 \%$ is below. The results of particle size distributions of the coarse and superfine powders of $H$. marmoreus are shown in Table 1 and Fig. 1. For coarse and superfine powders, the particle size distributions were $25.392 \mu \mathrm{m}$ and $2.102 \mu \mathrm{m}$, respectively, at $\mathrm{d}(0.1)$ and $542.109 \mu \mathrm{m}$ and $10.428 \mu \mathrm{m}$, respectively, at $\mathrm{d}(0.9)$. The average median diameter at $\mathrm{d}(0.5)$ was 168.085 $\mu \mathrm{m}$ for the coarse powder and $4.791 \mu \mathrm{m}$ for the superfine powder. These observations confirmed the effective reduction of the particle size of mushroom powder through the extensive milling process, as a result of superfine grinding technology. Superfine powder samples had the lowest span of $1.738 \mu \mathrm{m}$ indicating that these samples had a narrow particle size distribution compared to coarse powder 
Table 1. Particle size distribution of coarse and superfine Hypsizygus marmoreus mushroom powders

\begin{tabular}{ccccc}
\hline \multirow{2}{*}{ Sample } & \multicolumn{3}{c}{ Particle size $(\mu \mathrm{m})$} \\
\cline { 2 - 5 } & $\mathrm{d}(0.1)^{1)}$ & $\mathrm{d}(0.5)$ & $\mathrm{d}(0.9)$ & $\left.\operatorname{Span}^{2}\right)$ \\
\hline Coarse powder & 25.392 & 168.085 & 542.109 & 3.074 \\
Superfine powder & 2.102 & 4.791 & 10.428 & 1.738 \\
\hline
\end{tabular}

${ }^{1)} \mathrm{d}(0.1)$, size when $10 \%$ in total particle size distribution; $\mathrm{d}(0.5)$, size when $50 \%$ in total particle size distribution; $\mathrm{d}(0.9)$, size when $90 \%$ in total particle size distribution.

${ }^{2)}$ Span, distribution width of sample $=[\mathrm{d}(0.9)-\mathrm{d}(0.1)] / \mathrm{d}(0.5)$

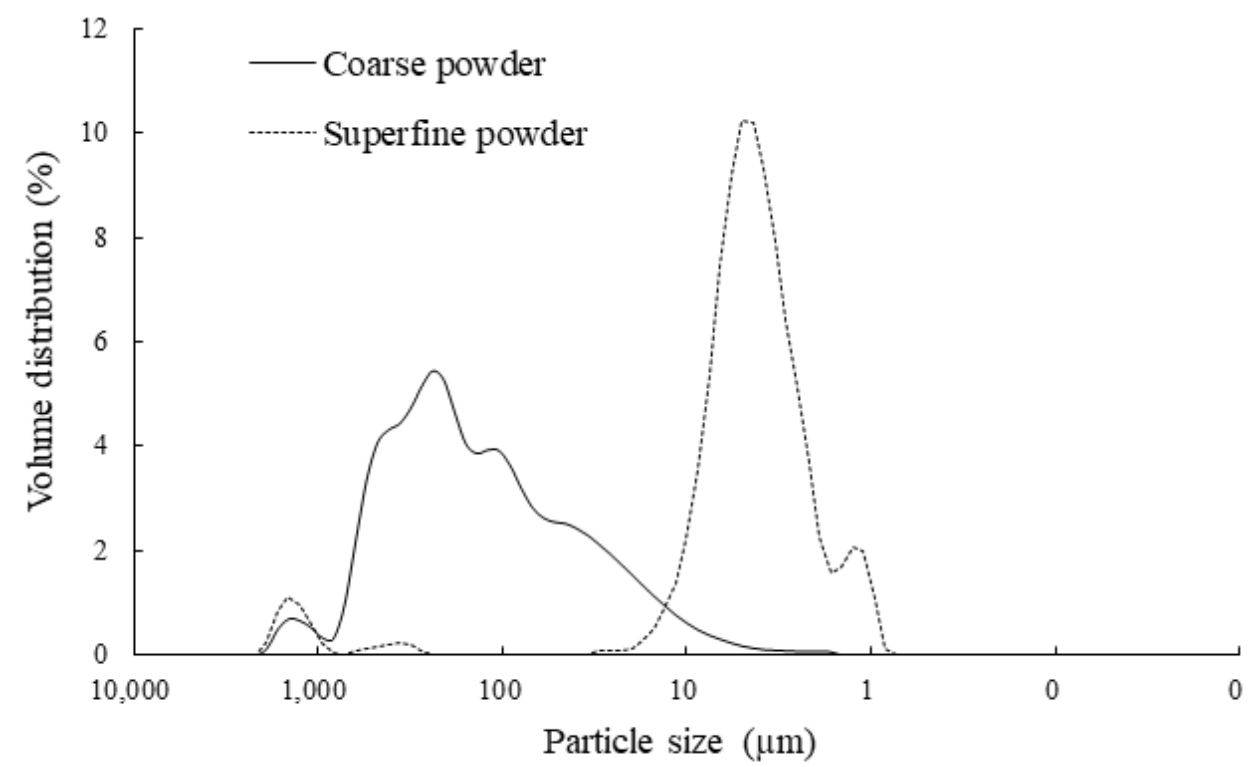

Fig. 1. Particle size distribution of Hypsizygus marmoreus mushroom powders.

samples. Similar results were obtained by Choi et al. (2012) and Lv et al. (2014) in their research on ultrafine Angelica gigas and Agrocybe chaxingu mushroom powders, respectively, which exhibited lower $\mathrm{d}(0.1), \mathrm{d}(0.5), \mathrm{d}(0.9)$, and span values for superfine-ground samples; and indicated that a lower span value corresponded to a narrow particle distribution yielding powder particles with a more uniform size.

Water absorption index, water solubility index, beta glucan content, and total dietary fiber contents

The WAI was calculated as the weight of the gel (obtained after discarding the supernatant) per unit of original dry solids and WSI as the weight of dry solids in the supernatant expressed as percentage of the original weight of the sample. Table 2 represents the WAI, WSI, $\beta$ glucan content, and total dietary fiber contents of the coarse and superfine mushroom powders. Superfine grinding increased WAI and total dietary fiber contents, as the superfine mushroom powder exhibited higher values, 5.79 $\mathrm{g} / \mathrm{g}$ and $28.5 \mathrm{~g} / 100 \mathrm{~g}$, respectively, than the coarse mushroom powder samples. Carvalho et al. (2010) and Zhao et al. (2008) reported that the WAI increased with a decrease in the particle size of corn starch and ginger powder, respectively, because smaller particles produced by superfine grinding had a greater contact area which in turn improved water absorption capacity. Additionally, size reduction of powders of the mushroom Inonotus obliquus by ball milling has been reported to improve the extractability of active ingredients in mushrooms (Wang et al., 2016). The 
Table 2. Water solubility index, water absorption index, $\beta$-glucan content, and total dietary fiber contents of Hypsizygus marmoreus mushroom powders

\begin{tabular}{ccccc}
\hline Sample & WAI $^{1)}$ & WSI $(\%)$ & $\beta$-Glucan (\%) & Total dietary fiber (\%) \\
\hline Coarse powder & $2.91 \pm 0.19^{\mathrm{a} 2)}$ & $51.33 \pm 0.94^{\mathrm{a}}$ & $30.08 \pm 0.46^{\mathrm{a}}$ & 27.30 \\
Superfine powder & $5.79 \pm 0.36^{\mathrm{b}}$ & $42.00 \pm 1.00^{\mathrm{b}}$ & $29.82 \pm 1.36^{\mathrm{a}}$ & 28.50 \\
\hline
\end{tabular}

${ }^{1)}$ WAI, water absorption index; WSI, water solubility index.

${ }^{2)}$ Values (Mean $\pm \mathrm{SD}, \mathrm{n}=3$ ) with different superscripts in the same column are significantly different at $\mathrm{p}<0.05$.

reduction in particle size did not affect the $\beta$-glucan content of the mushroom samples, as the coarse powder contained $30.08 \% \beta$-glucan and superfine powder contained $29.82 \%$. $\mathrm{Lv}$ et al. (2014) reported that superfine mushroom powders exhibited higher total dietary fiber content and WAI (water holding capacity) compared to the control sample, which was coarsely ground. In contrast, the coarse powder had a higher solubility index (51.33\%) than the superfine powder $(42.00 \%)$ which contradicted previous reports that superfine grinding technology improved the WSI.

Extraction yield, $\mathrm{pH}$, total soluble solids, total sugar contents, total polyphenol contents, and total flavonoid contents of Hypsizigus marmoreus hot water extracts

Table 3 presents the extraction yield, $\mathrm{pH}$, total soluble solid contents, total sugar contents, total polyphenolics contents, and total flavonoid content of hot-water extracts prepared from coarse and superfine H. marmoreus powders. Extracts prepared from the superfine mushroom powders exhibited the highest values for all the aforementioned parameters except total soluble solid contents, which was similar for both samples. Total polyphenolics contents, total sugar contents, and total flavonoid contents of extracts prepared from superfine powders were $83.91 \mathrm{mg}$ GAE/100 g, $5138.5 \mathrm{mg} / 100 \mathrm{~g}$, and $43.99 \mathrm{mgNE} / 100 \mathrm{~g}$, respectively. The extraction yield was $3.53 \%$ for the coarse powder and $6.07 \%$ for the superfine powder. The $\mathrm{pH}$ of concentrates prepared from the coarse and superfine powders was 6.04 and 6.17, respectively. Park and Ahn (2019) reported a similar effect of particle size on total polyphenols. Similarly, Jiang et al. (2017) reported that the solubility of flavonoids increased with a decrease in the particle size of Vaccinium bracteatum Thunb. leaf powder extracted in ethanol, which is consistent with our results. Additionally, particle size reduction has also been reported to increase extraction yield because smaller particle sizes shorten the path that the solvent has to travel, which in turn reduces the time required for maximum extraction of functional constituents of the sample (Yeop et al., 2017). Moreover, Speroni et al. (2019) reported that the polyphenol content and antioxidant capacity of olive pomace were improved due by micronization and granulometric fraction processing technologies. Additionally, Zhang et al. (2020) determined that superfine grinding improved the accessibility of functional compounds in milled Lycium ruthenicum Murray which in turn increased their antioxidant abilities.

\section{Morphological properties of Hypsizygus marmoreus mushroom powders}

Scanning electron microscopy (SEM) images of coarse and superfine H. marmoreus powders are shown in Fig. 2.

Table 3. Extraction yield, pH, total soluble solid contents, total sugar contents, total polyphenol contents, and total flavonoid contents of hot-water extracts of Hypsizygus marmoreus mushroom powders

\begin{tabular}{ccccccc}
\hline Sample & $\begin{array}{c}\text { Extraction yield } \\
(\%)\end{array}$ & $\mathrm{pH}$ & $\begin{array}{c}\text { TSS }{ }^{1)} \\
\left({ }^{\circ} \text { Brix }\right)\end{array}$ & $\begin{array}{c}\text { TS } \\
(\mathrm{mg} / 100 \mathrm{~g})\end{array}$ & $\begin{array}{c}\text { TP } \\
(\mathrm{mgGAE} / 100 \mathrm{~g})\end{array}$ & $\begin{array}{c}\text { TF } \\
(\mathrm{mgNE} / 100 \mathrm{~g})\end{array}$ \\
\hline Coarse powder & $3.53 \pm 0.48^{\mathrm{a} 2)}$ & $6.04 \pm 0.01^{\mathrm{a}}$ & $5.00 \pm 0.00^{\mathrm{a}}$ & $4,402.24 \pm 294.47^{\mathrm{a}}$ & $73.43 \pm 1.51^{\mathrm{a}}$ & $38.38 \pm 2.05^{\mathrm{a}}$ \\
Superfine powder & $6.07 \pm 0.25^{\mathrm{b}}$ & $6.17 \pm 0.01^{\mathrm{b}}$ & $5.00 \pm 0.00^{\mathrm{a}}$ & $5,138.50 \pm 334.90^{\mathrm{a}}$ & $83.91 \pm 0.98^{\mathrm{b}}$ & $43.99 \pm 1.88^{\mathrm{b}}$ \\
\hline
\end{tabular}

${ }^{1}$ TSS, total soluble solids; TS, total sugar; TP, total polyphenol; TF, total flavonoid.

${ }^{2)}$ Values (Mean $\pm \mathrm{SD}, \mathrm{n}=3$ ) with different superscripts in the same column are significantly different at $\mathrm{p}<0.05$. 
(A)

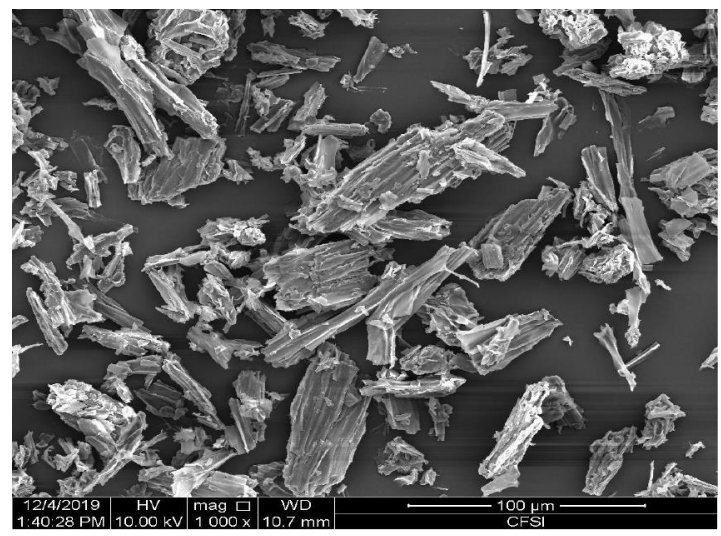

(B)

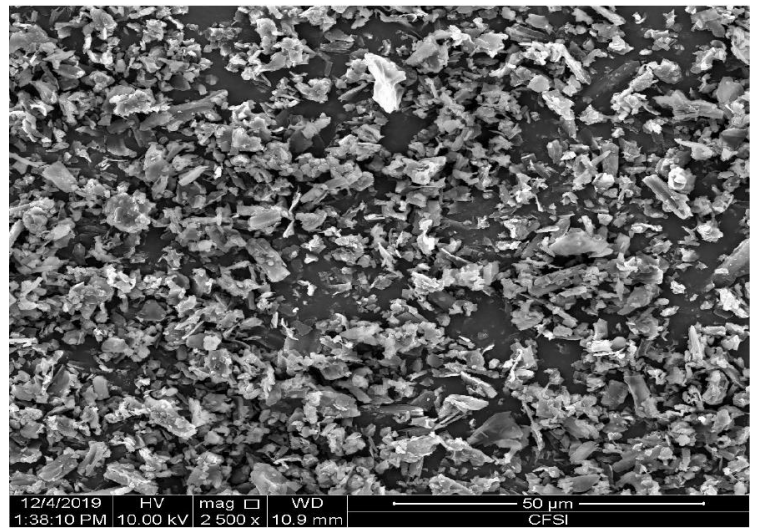

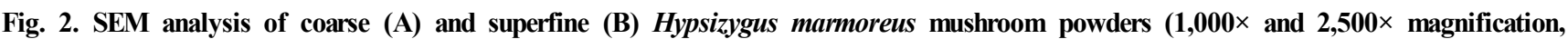
respectively).

The superfine grinding technology resulted in considerably smaller powder particles that were only distinguishable under increased magnification; hence, the magnification was set at 2,500× instead of $1,000 \times$ which was used for coarse powder samples. The SEM images indicated that both powders differed in either the shape or size of the particles, with coarse powder particles exhibiting irregular shapes, mostly rectangular, polygonal, and other random shapes; rough surfaces; and high porosity. In contrast, the superfine powder particles exhibited more uniformity in shape (appearing in rectangular, circular, and needle-like shapes) and reduced porosity, displaying a denser structure. This size uniformity of superfine-ground mushroom powder particles was explained by the lower span values (presented in the particle size distribution analysis). Lv et al. (2014) reported that lower span values corresponded to a more uniform particle size; similarly, in their findings, superfine grinding resulted not only in the reduction of particle size but also in significant modification of the powder structure owing to the extensive milling process consisting of flattening, aggregation, and fracturing of mushroom particles (Zhao et al., 2013). These findings indicate that superfine grinding significantly modifies the surface structure of the powder particles, which may affect the physicochemical properties of the samples.

\section{Taste and odor characteristics}

Electronic noses and electronic tongues are devices equipped with gas and chemical sensors, respectively, that human sensory evaluation and electronic tongue system confirmed the ability of electronic tongue and nose to evaluate the taste and odor characteristics of various samples (Bleibaum et al., 2002). These devices were used for the determination of odor and taste characteristics of mushroom extracts (Fig. 3). Extracts prepared from coarse and superfine H. marmoreus mushroom powders were analyzed for five different taste characteristics, including sourness, saltiness, umami, sweetness, and bitterness, and the results are displayed in a spider plot (Fig. 3A). Mushroom extracts prepared from superfine powders had high scores for sourness, umami, and sweetness values, while those from coarse powders had high bitterness scores. Similar findings were reported by Phat et al. (2016), who indicated that mushrooms with low umami taste scores had high bitterness scores and those with high umami taste levels had high saltiness scores. Discriminant function analysis (DFA) was used to highlight the differences or similarities between the mushroom extracts. DFA for taste and odor characteristics is shown in Fig. 3B and $\mathrm{C}$, respectively. Discriminant function 1 (DF1) and discriminant function 2 (DF2) were $100 \%$ and $0 \%$, respectively, indicating that the taste and odor characteristics of the coarse powder and superfine powder extracts were significantly different and therefore classified into two significantly different clusters. The DFA results for odor and taste characteristics confirmed the taste score results of the mushroom extracts displayed in the spider plot. Furthermore, in a study conducted by Qiu et al. (2019), size reduction affected sourness, bitterness, and 
(A)

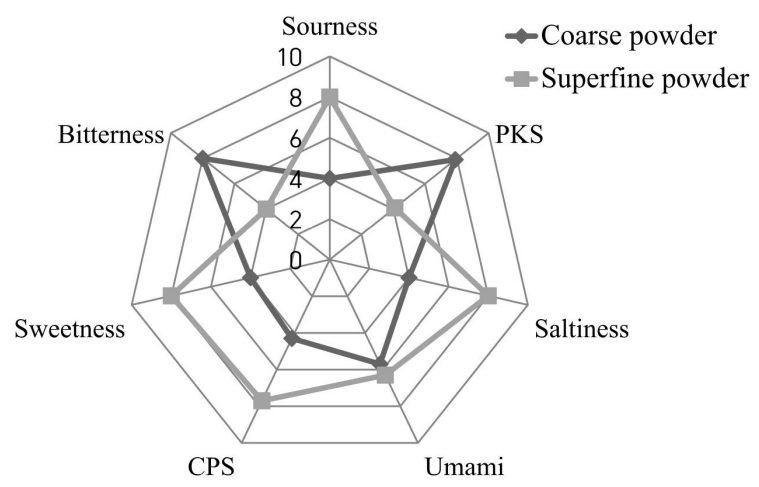

(B)

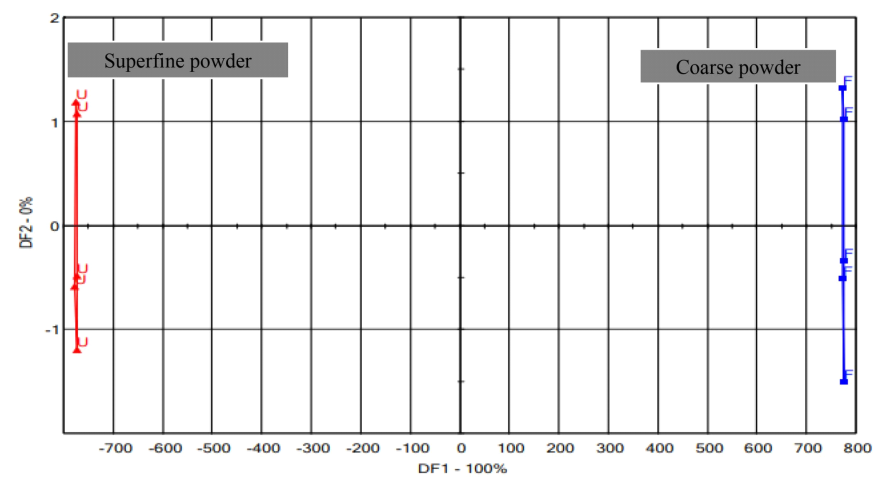

(C)

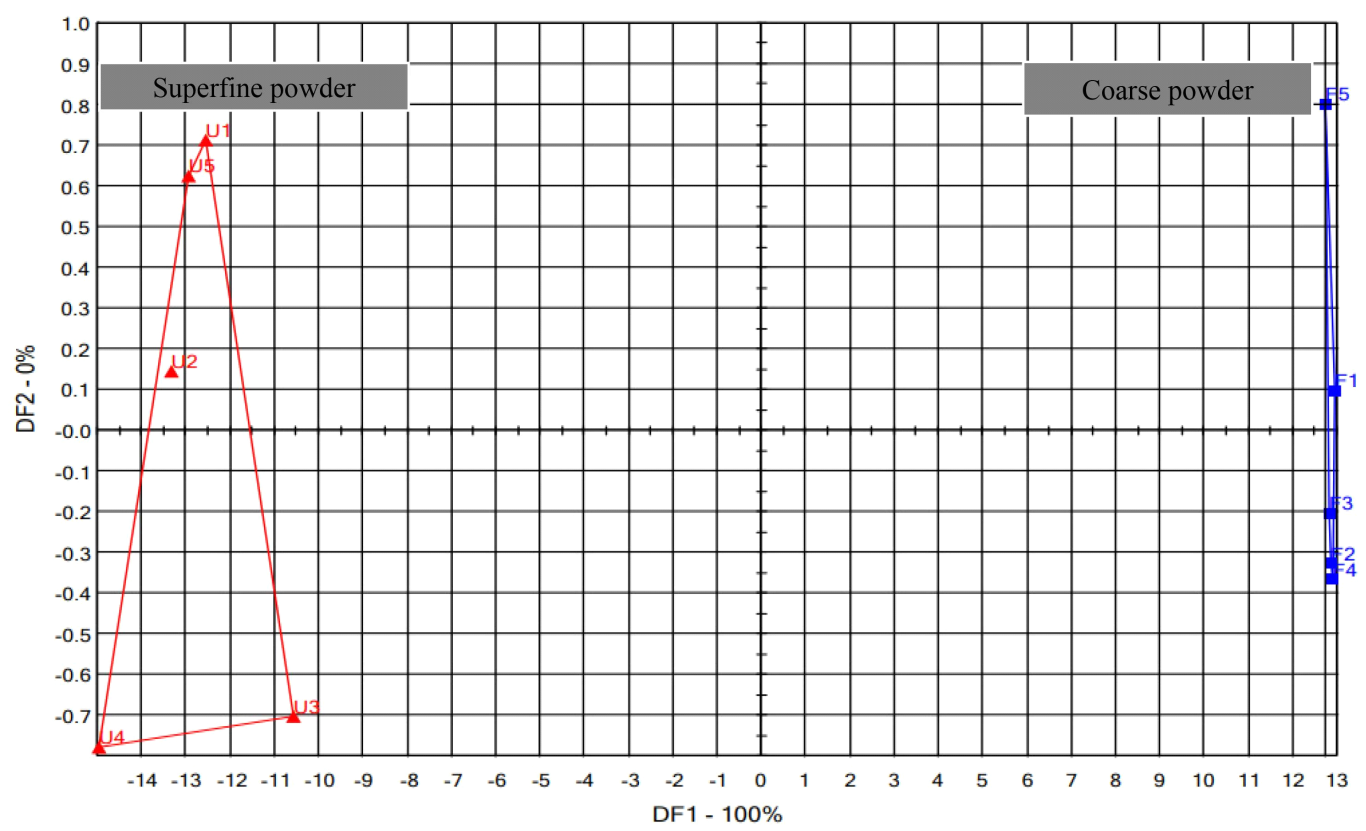

Fig. 3. Taste and odor characteristics of water extracts of Hypsizygus marmoreus mushroom powders.

A, radar representation of electronic tongue analysis; B, discriminant function analysis based on electronic tongue data; C, discriminant function analysis based on electronic nose data.

astringency of wasabi paste by increasing sourness while decreasing bitterness and astringency, which was possibly due to the grinding process that degraded taste substances.

In conclusion, our study found that particle size reduction through superfine grinding beneficially affected the physicochemical and morphological properties of mushroom powder samples and their water extracts. Therefore, the adoption of superfine milling in powder-processing industries could result in products with improved functional properties.

\section{Acknowledgements}

This research was supported by the Ministry of Education (MOE) and the National Research Foundation of Korea (NRF) through the "Leaders in Industry-university Cooperation+" Project.

\section{Conflict of interests}

The authors declare no potential conflict of interest. 


\section{ORCID}

Emmanuel Hitayezu

https://orcid.org/0000-0002-3822-3619

Yoon-Han Kang https://orcid.org/0000-0002-4450-0483

\section{References}

Abdulbari HA, Yeop A, Sandasam J, Pan SF, Abdulla S, Yusoff MM, Gimbun J. The effect of particle size and solvent type on the gallic acid yield obtained from Labisia pumila by ultrasonic extraction. MATEC Web of Conferences, 111, 1-5 (2017)

Bak WC, Park JH, Park YA, Ka KH. Determination of glucancontents in the fruiting bodies and mycelia of Lentinula edodes cultivars. Mycobiology, 42, 301-304 (2014)

Beullens K, Meszaros P, Vermeir S, Kirsanov D, Legin A, Buysens S, Cap N, Nicolai B, Lammertyn J. Analysis of tomato taste using two types of electronic tongues. Sens Actuators B, 131, 10-17 (2008)

Bleibaum RN, Stone H, Tan T, Labreche S, Saint-Martin E, Isz $\mathrm{S}$. Comparison of sensory and consumer results with electronic nose and tongue for apple juices. Food Qual Preference, 13, 409-422 (2002)

Carvalho CWP, Takeiti CY, Onwulata CI, Pordesimo LO. Relative effect of particle size on the physical properties of corn meal extrudates: Effect of particle size on the extrusion of corn meal. J Food Eng, 98, 103-109 (2010)

Choi KO, Lee IA, Paik SYR, Kim DE, Lim JD, Kang WS, Ko SH. Ultrafine Angelica gigas powder normalizes ovarian hormone levels and has antiosteoporosis properties in ovariectomizedrats: Particle size effect. J Med Food, 15, 863-872 (2012)

Dai J, Wu Y, Che SW, Song Z, Yin HP, Wang M, Tan J. Sugar compositional determination of polysaccharides from Dunaliella salina by modified RP-HPLC method of precolumn derivatization with 1-phenyl-3-methyl-5-pyrazolone. Carbohydr Polym, 82, 629-635 (2010)

Dong W, Hu R, Long Y, Li H, Zhang Y, Kexue Z, Chu $Z$. Comparative evaluation of the volatiles and taste properties of roasted coffee beans as affected by drying method and detected by electronic nose, electronic tongue, and HS-SPME-GC-MS. Food Chem, 272,
723-731 (2019)

Han D, Zhang CH, Fauconnier ML, Jia W, Wang JF, Hu FF, Xie DW. Characterization and comparison of flavor compounds in stewed pork with different processing methods. LWT-Food Sci Technol, 144, 1-10 (2021)

$\mathrm{Hu}$ J, Chen Y, Ni D. Effect of superfine grinding on quality and antioxidant property of fine green tea powders. LWT-Food Sci Technol, 45, 8-12 (2012)

Jiang L, Xu QX, Qiao M, Ma FF, Thakur K, Wei ZJ. Effect of superfine grinding on properties of Vaccinium bracteatum Thunb leaves powder. Food Sci Biotech, 26, 1571-1578 (2017)

Kang DY, Hitayezu E, Han IH, Kim JS, Jo YM, Kang YH. Physicochemical characteristics and antioxidant activities of solvent fractions from ethanol extract of Wasabia koreana Nakia leaf. Korean J Food Preserv, 26, 586-593 (2019)

Kim EJ, Kim JH. Physiological activities of water extract and solvent fractions of Grifola frondosa. J Mushrooms, 13, 192-198 (2015)

Koh GH, Lee CH, Yoon J. Physicochemical characteristics of coffee brews using different brewing methods. Food Eng Prog, 24, 110-119 (2020)

Lee HJ, Sung JH, Choi JY, Cho JS, Lee YM, Chung HS, Moon KD. Evaluation of the quality characteristics in omija (Schizandra chinensis Baillon) power tea. Korean J Food Sci Technol, 48, 42-47 (2016)

Lee YL, Jian SY, Lian PY, Mau JL. Antioxidant properties of extracts from a white mutant of the mushroom Hypsizigus marmoreus. J Food Comp Anal, 21, 116-124 (2008)

Lee YL, Yen MT, Mau JL. Antioxidant properties of various extracts from Hypsizigus marmoreus. Food Chem, 104, $1-9$ (2007)

Lv G, Zhang ZF, Pan H, Fan L. Effect of physical modification of mushroom (A. chaxingu) powders on their physical and chemical properties. Food Sci Technol Res, 20, 731-738 (2014)

Ming J, Chen L, Hong H, Li J. Effect of superfine grinding on the physicochemical, morphological and thermogravimetric properties of Lentinus edodes mushroom powders. J Sci Food Agric, 95, 2431-2437 (2014)

Park JH, Ahn JJ. Antioxidant activities of powdered and ultra-fine powdered Ulmus davidiana var. japonica. 
Korean J Community Living Sci, 27, 343-350 (2016)

Phat C, Moon B, Lee C. Evaluation of umami taste in mushroom extracts by chemical analysis, sensory evaluation, and an electronic tongue system. Food Chem, 192, 1068-1077 (2016)

Pinto MDS, Lajolo FM, Genovese MI. Bioactive compounds and antioxidant capacity of strawberry jams. Plant Foods Hum Nutr, 62, 127-131 (2007)

Qiu L, Zhang, M, Bhandari B, Fang Z, Liu Y. Size reduction of raw material powder: The key factor to affect the properties of wasabi (Eutrema yunnanense) paste. Advanced Powder Technol, 30, 1544-1550 (2019)

Seo MC, Ko JY, Song SB, Lee JS, Kang JR, Kwak DY, Oh BG, Yoon YN, Nam MH, Jeong HS, Woo KS. Antioxidant compounds and activities of foxtail millet, proso millet and sorghum with different pulverizing methods. J Korean Soc Food Sci Nutr, 40, 790-797 (2011)

Shu TS, Lee G, Seo YK, Lee KP, Kim DJ. Micro particle technology in food science. Food Sci Ind, 37, 17-21 (2004)

Speroni CS, Stiebe J, Guerra DR, Beutinger Bender AB, Ballus CA, dos Santos DR, Pont Morisso FD, da Silva LP, Emanuelli T. Micronization and granulometric fractionation improve polyphenol content and antioxidant capacity of olive pomace. Ind Crop Prod, 137, 347-355 (2019)

Suzuki T, Umehara K, Tashiro A, Kobayashi Y, Dohra H, Hirai $\mathrm{H}$, Kawagishi $\mathrm{H}$. An antifungal protein from the clinary-medicinal bechmshroom, Hypsizygus marmoreus (Peck) Bigel (Agaricomycetideae), Int J Med Mushrooms, 13, 27-31 (2011)
Wang J, Wang C, Li W, Pan Y, Yuan G, Chen H. Ball milling improves extractability and antioxidant properties of the active constituents of mushroom Inonotus obliquus powders. Int J Food Sci Technol, 51, 2193-2200 (2016)

Yousf N, Nazir F, Salim R, Ahsan H, Sirwal A. Water solubility index and water absorption index of extruded product from rice and carrot blend. J Pharmacog Phytochem, 6, 2165-2168 (2017)

Zhang J, Dong Y, Nisar T, Fang Z, Wang ZC, Guo Y. Effect of superfine-grinding on the physicochemical and antioxidant properties of Lycium ruthenicum Murray powders. Powder Technol, 372, 68-75 (2020)

Zhao X, Chen J, Chen F, Wang X, Zhu Q, Ao Q. Surface characterization of corn stalk superfine powder studied by FTIR and XRD. Colloids and Surfaces B: Biointerfaces, 104, 207-212 (2013)

Zhao X, Yang Z, Gai G, Yang Y. Effect of superfine grinding on properties of ginger powder. J Food Eng, 91, 217-222 (2009)

Zhao X, Zhu H, Zhang G, Tang W. Effect of superfine grinding on the physicochemical properties and antioxidant activity of red grape pomace powders. Powder Technol, 286, 838-844 (2015)

Zhou CL, Mi L, Hu XY, Zhu BH. Evaluation of three pumpkin species: Correlation with physicochemical, antioxidant properties and classification using SPME-GCMS and E-nose methods. J Food Sci Technol, 54, 31183131 (2017)

Zhou R, Kang YH. Synergistic interaction of Auricularia auricula-judae polysaccharide with yam starch: Effects on physicochemical properties and in vitro starch digestibility. Food Sci Biotechnol, 27, 1579-1588 (2018) 